\title{
Intention of Continuing to use the Hospital Information System: Integrating the elaboration-likelihood, social influence and cognitive learning
}

\author{
Mehrdad Farzandipour ${ }^{1}$, Hashem Mohamadian ${ }^{2}$, Niloufar Sohrabi ${ }^{3}$
}

${ }^{1} \mathrm{Ph} . \mathrm{D}$. of Health Information Management, Associate Professor, Research Centre for Health Information Management, Department of Health Information Management, School of Allied Medical Sciences, Kashan University of Medical Sciences, Kashan, Iran

${ }^{2}$ Ph.D. of Health Education, Assistant Professor, Research Centre for Health-Related Social Determinates, Faculty of Health, Department of Health Education and Promotion, Ahvaz Jundishapur University of Medical Sciences, Ahvaz, Iran

${ }^{3}$ M.Sc. of Health Information Technology, Research Centre for Health Information Management, Department of Health Information Management, School of Allied Medical Sciences, Kashan university of Medical Sciences, Kashan, Iran

\section{Type of article: Original}

\begin{abstract}
Introduction: Anticipating effective factors in information system acceptance by using persuasive messages, is one of the main issues less focused on so far. This is one of the first attempts at using the elaboration-likelihood model combined with the perception of emotional, cognitive, self-efficacy, informational and normative influence constructs, in order to investigate the determinants of intention to continue use of the hospital information system in Iran.

Methods: The present study is a cross-sectional survey conducted in 2014. 600 nursing staff were chosen from clinical sectors of public hospitals using purposive sampling. The questionnaire survey was in two parts: Part one was comprised of demographic data, and part two included 52 questions pertaining to the constructs of the model in the study. To analyze the data, structural equation model using LISREL 8.5 software was applied.

Result: The findings suggest that self-efficacy $(t=6.01, \beta=0.21)$, affective response $(t=5.84, \beta=0.23)$, and cognitive response $(\mathrm{t}=4.97, \beta=0.21)$ explained $64 \%$ of the variance for the intention of continuing to use the hospital information system. Furthermore, the final model was able to explain 0.46 for self-efficacy, 0.44 for normative social influence, 0.52 for affective response, 0.55 for informational social influence, and 0.53 for cognitive response.

Conclusion: Designing the necessary mechanisms and effective use of appropriate strategies to improve emotional and cognitive understanding and self-efficacy of the nursing staff is required, in order to increase the intention of continued use of the hospital information system in Iran.

Keywords: Hospital information system; Informative and normative social influence; Cognitive and affective perceive; Structural equation modeling
\end{abstract}

\section{Introduction}

\subsection{Background and study logic}

Technological advancements have changed the face of the world. In the information and communication technology era, information is as the main artery and life-giving force in providing health care. An information system is all that which contributes to the distribution within an organization, and without the information system, the organization would not survive. The purpose of these systems is to support hospital activities in practical, tactical, and strategic levels in order to provide better service to patients (1). The health information system (HIS) in hospitals can provide

\section{Corresponding author:}

Assistant Professor Dr. Hashem Mohamadian, Research Centre for Health-Related Social Determinates, Faculty of Health, Department of Health Education and Promotion, Ahvaz Jundishapur University of Medical Sciences, Ahvaz, Iran. Tel: +98.6133738479, Email: hmohamadian@razi.tums.ac.ir

Received: February 04, 2016, Accepted: June 05, 2016, Published: December 2016

iThenticate screening: May 09, 2016, English editing: October 10, 2016, Quality control: November 03, 2016

(C) 2016 The Authors. This is an open access article under the terms of the Creative Commons Attribution-NonCommercialNoDerivs License, which permits use and distribution in any medium, provided the original work is properly cited, the use is non-commercial and no modifications or adaptations are made. 
an opportunity to reduce human error, increase speed and accuracy of processes efficiency, and ease of access to timely information for health cycles, significant economic savings as well as inter-sectoral coordination and cooperation (2). Three main aspects must be considered to launch HIS: 1) The hardware and network, 2) software, and 3) Users. The users are the owners and main actors in the systems. The success and failure of information systems is related to the adoption of technologies by their users (3). What causes a person to accept new technology? Are these factors relying on the characteristics of the technology or the people? How and in what manner do these factors influence on Information Technology (IT) adoption? Nursing comprises a large segment of the health care workforce (4). Many healthcare organizations are faced with resistance to the use and application of IT in nursing and other health sectors. Therefore, it is necessary to pay special attention to address these challenges as the key factors of success in the IT systems (5). There are several theories regarding the acceptance of IT systems such as the Technology Acceptance Model (TAM) (6), Diffusion of Innovation Theory (IDT) (7) and the Unified Theory of Acceptance and Use of Technology (UTAUT) (8). The main focus of these theories is on users' behavior incentives such as perceptions of usefulness and comparative advantage. Unfortunately, these theories have been less considered on the processes of influence. Our understanding of the nature and mechanisms of processes of influence on technology adoption is not enough. One theoretical perspective that may facilitate our understanding of influence processes in IT acceptance is the elaboration-likelihood model (ELM) (9). In today's organizations, managers, as well as their expertise fields, should be familiar with the techniques of the influence process with others. Managers, through influence on the attitudes and beliefs of their personnel, are better able to achieve their organizational goals. Social influence is a process in which before individuals intend to use a new information system will emulate the experiences of other people. Researchers identified two types of normative and informational social influences in decision-making areas (10). Social cognitive theory explains human behavior in a triple cross-linking structure or interactions between behavior, environment, and individual factors. A key assumption of social cognitive theory is that people tend to control the events that affect their lives and they consider themselves as the Impact Factor. This sense of influence in the actions' cognitive and emotional processes are called self-efficacy (11). The literature indicated that self-efficacy has become an important construct in information systems researches (12). Many studies have shown self-efficacy as a strong predictor of health behavioral intention (13). However, few studies have used self-efficacy in order to promote information systems. This is one of the first attempts at using the ELM model and combined with the perception of emotional, cognitive, self-efficacy, Informational and normative influence constructs in order to investigate the determinants of intention to continue using the HIS in the Iran. The results of this study will provide a new perspective in order to design effective programs to accept and implement an HIS in the Iranian's nursing personnel. Managers can apply a variety of strategies in order to motivate their employees. Therefore, it is necessary to consider the information-processing routes and this knowledge as a useful step towards the implementation of the correct HIS. A research model of this study is proposed in Figure 1. A new research model was founded for the examination of the relationship between the elaboration-likelihood (source credibility and quality of the message), social influence (normative and informative), and cognitive learning (self-efficacy) models about the intention of continuing to use the HIS among nurses.

\subsection{Hypotheses}

Hypotheses examined in this study were:

1) Employees experiencing persuasive messages from HIS with higher levels of source credibility tend to perceive higher levels of normative social influence.

2) Employees experiencing persuasive messages from HIS with higher levels of source credibility tend to have been more affectively perceived.

3) Employees experiencing persuasive messages from HIS with higher levels of affective perception tend to perceive higher levels of self-efficacy.

4) Employees experiencing persuasive messages from HIS with higher levels of argument quality tend to have been more cognitively perceived.

5) Employees experiencing persuasive messages from HIS with higher levels of cognitive perception tend to perceive higher levels of self-efficacy.

6) Employees experiencing persuasive messages from HIS with higher levels of argument quality tend to perceive higher levels of informative social influence.

7) Employees experiencing persuasive messages from HIS with higher levels of normative social influence tend to have been more self-efficacy perceived.

8) Employees experiencing persuasive messages from HIS with higher levels of informative social influence tend to have been more self-efficacy perceived.

9) Employees with higher levels of self-efficacy tend to have higher levels of behavior intention. 


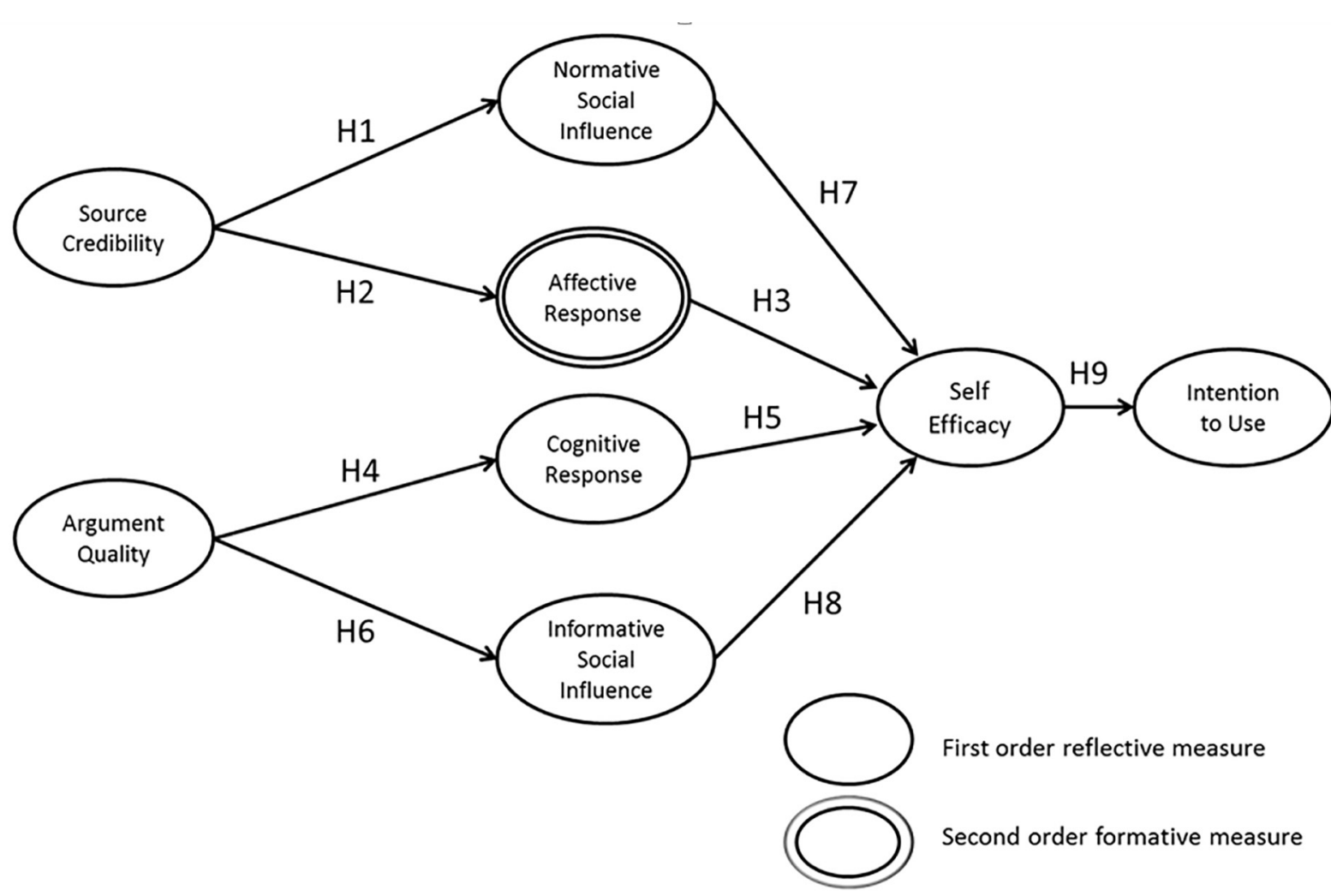

Figure 1. The Initial model of this study

\section{Material and Methods}

This research was carried out by nurses, all of whom were users of HIS in three companies (Tiraje computer, Mykroafzar Qeshm and Peivand data), and were trained by government hospitals for clinical practice. According to the report by Farzandipour et al., in their study entitled, 'Hospital Information System User Needs Analysis: A vendor survey', five major suppliers of hospital information systems in eight teaching hospitals were compared (14). They found that the three company's functional requirements in nursing units appeared to be good, average, and poor, respectively. For determining structural equation modeling (SEM) sample size, the sample size for the path analysis in this study based on the latent factors is determined not based on variables. Therefore, according to the eight latent factors in the study and the likely missing data on the respondents $(25 \%)$ - sample size were estimated for each of the information systems on about 200 people. Also, according to Kline (2015), if the sample size is 200 and above, it can be sufficient for the sample compliance (15). Nonprobability Sampling was selected in this study. After review of the existing literature and previous validated questionnaires, an initial questionnaire was prepared. Then, the questionnaire was submitted to eleven experts to determine its face and content validity. Eleven panel experts with two management professors, five experienced professionals in the health information management department and human-resource department, and four Msc management students were conducted to discuss the appropriateness of the research questionnaire items. The final questionnaire was consisted of 59 items divided into two parts: 1) demographic information users, including: name of work location, gender, marital status, education, job experience, familiarity with computers, interaction in each work shift. 2) The numbering of 52 questions related to the constructs of the model, respectively: $1-6$ for credible source, 7-16 for argument quality, $17-25$ for normative social influence, 26-28 for informational social influence, 29-35 in affective response, 36-42 in cognitive response, 43-49 for self-efficacy, and 50-52 for intention of continuing to use HIS. All the items used a five-point Likert scale with anchors from strongly disagree (1) to strongly agree (5). To assess the content validity, the content validity rate (CVR) and the content validity index (CVI) were determined (16). Afterwards, the questionnaire's internal consistency was examined by Cronbach's alpha. Construct validity was evaluated in terms of convergent and discriminant validity (17). To evaluate convergent validity, three criteria were used. First, standardized factor loadings are greater than 0.7 . Second, composite reliability (CR) is greater than the cut off 0.7 . Third, the average variance extracted (AVE) is greater than the benchmark of 0.5 (18). To assess the discriminant validity, the root square of AVE and all reflective inter-construct correlations were compared (19). The structural equation modeling 
http://www.ephysician.ir

and the path analysis are used in testing the research hypotheses applying LISREL software, version 8.5 (20). As recommended by a number of researchers, multiple criteria for goodness of fit were utilized in this research to evaluate the goodness of fit for models tested in confirmatory factor analysis (CFA) and SEM (21). These criteria consist of the following measures of model fit: chip-square; normed chip-square (the ratio of the chip-square to its degrees of freedom (df)); standardized root mean-square residual (SRMR); comparative fit index (CFI); and RootMean-Square Error of Approximation (RMSEA) (22).

\section{Results}

In this study, 551 questionnaires were finally returned. 20 questionnaires were incomplete. Thus, 531 questionnaires were usable, resulting in a response rate of $88.5 \%$. Table 1 shows the characteristics of the respondents. In this research, a two-stage analysis procedure has been selected for the analysis.

Table 1. Participant demographic information.

\begin{tabular}{|c|c|c|c|}
\hline \multicolumn{2}{|l|}{ Variables } & $\mathrm{n}$ & $\%$ \\
\hline \multirow[t]{4}{*}{ Company Name } & Peyvand Dadeha & 186 & 0.35 \\
\hline & Gheshm microware & 182 & 0.34 \\
\hline & Tirazheh Computer & 163 & 0.31 \\
\hline & Total & 531 & 100 \\
\hline \multirow[t]{3}{*}{ Sex } & Male & 108 & 20 \\
\hline & Female & 423 & 80 \\
\hline & Total & 531 & 100 \\
\hline \multirow[t]{3}{*}{ Marital Status } & Single & 188 & 0.35 \\
\hline & Married & 343 & 0.65 \\
\hline & Total & 531 & 100 \\
\hline \multirow[t]{5}{*}{ Education } & Technician & 14 & 0.025 \\
\hline & BS & 505 & 0.95 \\
\hline & MA & 10 & 0.02 \\
\hline & Doctorate & 2 & 0.005 \\
\hline & Total & 531 & 100 \\
\hline \multirow[t]{6}{*}{ Career Experience (year) } & $<1$ & 73 & 0.13 \\
\hline & $1-5$ & 179 & 0.33 \\
\hline & $6-11$ & 154 & 0.29 \\
\hline & $12-15$ & 70 & 0.13 \\
\hline & $>15$ & 55 & 0.12 \\
\hline & Total & 531 & 100 \\
\hline \multirow[t]{6}{*}{ Familiarity with computer } & Very little & 17 & 0.03 \\
\hline & Little & 93 & 0.18 \\
\hline & Medium & 325 & 0.61 \\
\hline & Very & 77 & 0.14 \\
\hline & Very much & 19 & 0.04 \\
\hline & Total & 531 & 100 \\
\hline \multirow[t]{7}{*}{ Interaction with HIS (hour) } & $<0.5$ & 95 & 0.18 \\
\hline & $0.5-1$ & 147 & 0.28 \\
\hline & $1-2$ & 137 & 0.26 \\
\hline & $2-3$ & 82 & 0.15 \\
\hline & $3-4$ & 30 & 0.055 \\
\hline & $>4$ & 40 & 0.075 \\
\hline & Total & 531 & 100 \\
\hline
\end{tabular}

\subsection{Measurement model}

A critical step of SEM is the assessment of the hypothesized measurement model, prior to the analysis of the structural equation model. All its variables were examined for relevance. This was performed by producing onefactor congeneric models for all latent constructs. One-factor congeneric models utilizing maximum likelihood CFA were evaluated for the hypothesized latent constructs of credible source, argument quality, normative social 
influence, informational social influence, affective response, cognitive response, self-efficacy, and intention of continuing to use HIS. The maximum likelihood method is used in CFA analysis. The one-factor congeneric model of credible source variable was tested. The model initially had a good fit. $\mathrm{P}=0.038, \mathrm{CMIN} / \mathrm{DF}=2.35, \mathrm{RMR}=$ $0.009, \mathrm{CFI}=1$ and $\mathrm{RMSEA}=0.050$.

Table 2. Factor loading and reliability

\begin{tabular}{|l|c|c|c|}
\hline Variable & Factor Loading & Composite reliability & Average variance extracted \\
\hline SC & & 0.93 & 0.68 \\
\hline SC1 & 0.81 & & \\
\hline SC2 & 0.90 & & \\
\hline SC3 & 0.87 & & \\
\hline SC4 & 0.88 & & \\
\hline SC5 & 0.71 & & 0.66 \\
\hline SC6 & 0.77 & & \\
\hline AQ & & 0.94 & \\
\hline AQ1 & 0.77 & & \\
\hline AQ2 & 0.83 & & \\
\hline AQ3 & 0.89 & & \\
\hline AQ4 & 0.81 & & \\
\hline AQ5 & 0.79 & & \\
\hline AQ6 & 0.89 & & \\
\hline AQ7 & 0.78 & & \\
\hline AQ8 & 0.72 & & \\
\hline NI & & 0.81 & \\
\hline NI1 & 0.56 & & \\
\hline NI2 & 0.72 & & \\
\hline NI3 & 0.73 & & \\
\hline NI4 & 0.85 & & \\
\hline II & & 0.80 & \\
\hline II1 & 0.81 & & \\
\hline II2 & 0.75 & & \\
\hline II3 & 0.71 & & \\
\hline CR & & & \\
\hline CR1 & 0.53 & & \\
\hline CR2 & 0.67 & & \\
\hline CR3 & 0.84 & & \\
\hline CR4 & 0.83 & & \\
\hline CR5 & 0.72 & & \\
\hline SE & & & \\
\hline SE1 & 0.53 & & \\
\hline SE2 & 0.56 & & \\
\hline SE3 & 0.81 & & \\
\hline SE4 & 0.85 & & \\
\hline SE5 & 0.79 & & \\
\hline BI & & & \\
\hline BI1 & 0.85 & & \\
\hline BI2 & 0.75 & & \\
\hline AR & & & \\
\hline AR1 & 0.57 & & \\
\hline AR2 & 1 & & \\
\hline AR3 & 0.58 & & \\
\hline AR4 & 0.87 & & \\
\hline AR5 & 0.65 & & \\
\hline AR6 & 0.85 & & \\
\hline & & & \\
\hline
\end{tabular}


All the remaining items were loaded on this factor, as the factor loading ranged from a low of 0.71 to a high of 0.90 . The one-factor congeneric model of argument quality variable was tested. The model initially had a good fit. $\mathrm{P}=$ $0.027, \mathrm{CMIN} / \mathrm{DF}=1.88, \mathrm{RMR}=0.012, \mathrm{CFI}=1$ and $\mathrm{RMSEA}=0.041$. All the remaining items were loaded on this factor, as the factor loading ranged from a low of 0.51 to a high of 0.79 . The one-factor congeneric model of normative social influence variable was tested. The model had a good fit. $\mathrm{P}=0.417, \mathrm{CMIN} / \mathrm{DF}=0.875, \mathrm{RMR}=$ $0.008, \mathrm{CFI}=1$ and $\mathrm{RMSEA}=0.000$. All the remaining items were loaded on this factor, as the factor loading ranged from a low of 0.37 to a high of 0.55 . The one-factor congeneric model of informational social influence variable was tested. The Fit was perfect. Also, the factor loading ranged from a low of 0.50 to a high of 0.66. The two-factor congeneric model of affective response variable was tested. The model had a good fit. $\mathrm{P}=0.036, \mathrm{CMIN} / \mathrm{DF}=2.132$, $\mathrm{RMR}=0.044, \mathrm{CFI}=0.99$ and $\mathrm{RMSEA}=0.046$. All the remaining items were loaded on this factor, as the factor loading ranged from a low of 0.57 to a high of 0.87 . The one-factor congeneric model of cognitive response variable was tested. The model had a good fit. $\mathrm{P}=0.396, \mathrm{CMIN} / \mathrm{DF}=1.017, \mathrm{RMR}=0.014, \mathrm{CFI}=1$ and $\mathrm{RMSEA}=0.006$. All the remaining items were loaded on this factor, as the factor loading ranged from a low of 0.53 to a high of 0.83 . The one-factor congeneric model of self-efficacy variable was tested. The model had a good fit. The model indicates the good fit based on assessment of model's fit indices. $\mathrm{P}=0.679, \mathrm{CMIN} / \mathrm{DF}=0.577, \mathrm{RMR}=0.006, \mathrm{CFI}=1$ and $\mathrm{RMSEA}=0.000$. All remaining items were loaded on this factor, as the factor loading ranged from a low of 0.53 to a high of 0.85 . The one-factor congeneric model of intention of continuing to use HIS variable was tested. The model had the good fit based on assessment of model's fit indices. The Fit was perfect. Also, all the remaining items were loaded on this factor, as the factor loading ranged from a low of 0.32 to a high of 0.85 . As shown in Table 2 , the convergent validity of this exploratory study is adequate. Table 3 provides evidence of sufficient discriminant validity in which the square root of the AVE is greater than all the inter-construct correlations. The internal reliability of the items was studied by Cronbach's alpha coefficient. As seen in Table 2, the reliability coefficients of the scale's constructs were in the range of 0.67 to 0.92 , indicating that the tool can make stable measurements.

Table 3. Mean, standard deviation, and correlation among major constructs $(n=531)$.

\begin{tabular}{|l|l|l|l|l|l|l|l|}
\hline Variable & 1 & 2 & 3 & 4 & 5 & 6 & 7 \\
\hline Mean & 21.00 & 30.00 & 27.90 & 10.50 & 19.70 & 21.50 & 9.50 \\
\hline Standard deviation & 5.16 & 7.69 & 6.44 & 2.65 & 5.07 & 5.31 & 2.61 \\
\hline 1 Source credibility & 0.82 & & & & & & \\
\hline 2 Argument quality & 0.69 & 0.81 & & & & & \\
\hline 3 Normative influence & 0.59 & 0.51 & 0.72 & & & & \\
\hline 4 Informational influence & 0.59 & 0.70 & 0.50 & 0.75 & & & \\
\hline 5 Cognitive response & 0.52 & 0.73 & 0.47 & 0.63 & 0.73 & & \\
\hline 6 Self-efficacy & 0.46 & 0.59 & 0.48 & 0. & 0.59 & 0.72 & \\
\hline 7 Behavior intention & 0.59 & 0.66 & 0.53 & 0.59 & 0.68 & 0.60 & 0.83 \\
\hline
\end{tabular}

Note: Diagonal elements are the square root of average variance extracted (AVE) of the reflective scales. Off diagonal elements are correlations between construct.

\subsection{Structural model}

The result of the initial structural model is shown in Table 4. The fit indices did not reach the desired level. Thus, some of the paths were revised in the diagram in order to achieve a satisfactory level of the fitness model. Figure 2 shows the explanatory power as the variance $\left(\mathrm{R}^{2}\right)$ in key endogenous constructs was 0.52 for the affective response, 0.53 for the cognitive response, 0.44 for normative influence, 0.55 for informational influence, 0.46 for self-efficacy and 0.64 for behavior intention. This greatly exceeded 10\%, which was suggested by Falk \& Miller (1992) as an indication of substantive explanatory power (23). Source credibility of the persuasive message has significant influences on normative influence $(\beta=0.35, \mathrm{p}<0.01)$ and affective response $(\beta=0.31, \mathrm{p}<0.01)$ among nurses for intention of continuing to use HIS. Hence, $\mathrm{H} 1$ and $\mathrm{H} 2$ were supported. Furthermore, the explanatory power as the variance $\left(\mathrm{R}^{2}\right)$ was to normative influence 0.44 and for effective response 0.52 , respectively. While argument quality of the persuasive message has significant effects on cognitive response $(\beta=0.37, p<0.01)$ and informational social influence $(\beta=0.72, p<0.001)$. Hence, H3 and H4 were supported. Furthermore, the explanatory power as the variance $\left(\mathrm{R}^{2}\right)$ was in cognitive response 0.53 and for informational social influence 0.55 , respectively. The normative social influence $(\beta=0.13, p<0.001)$, affective response $(\beta=0.13, p<0.001)$, informational social influence $(\beta=0.18, p<0.001)$, and cognitive response $(\beta=0.21, p<0.001)$ explained $46 \%$ of the variance $\left(R^{2}\right)$ of self-efficacy. Cognitive response was the most predictor variable for self-efficacy among them. Hence, H5, H6, H7and H8 were supported. The self-efficacy $(\beta=0.21, \mathrm{p}<0.001)$, and affective response $(\beta=0.23, \mathrm{p}<0.001)$, and 
cognitive response $(\beta=0.21, \mathrm{p}<0.001)$ explained $46 \%$ of the variance $\left(\mathrm{R}^{2}\right)$ of intention of continuing to use HIS. Hence, $\mathrm{H} 9$ were supported.

Table 4. Fitting Model Indexes

\begin{tabular}{|l|l|l|l|l|l|l|l|l|l|}
\hline Index & Chi-Square & $\mathrm{X}^{2} / \mathrm{df}$ & RMSEA & CFI & GFI & AGFI & NFI & NNFI & IF \\
\hline Critical amount & --- & $<3$ & $<0.05$ & $>0.9$ & $>0.9$ & $>0.9$ & $>0.9$ & $>0.9$ & $>0.9$ \\
\hline Primary model & 557.28 & 30.96 & 0.24 & 0.89 & 0.79 & 0.58 & 0.89 & 0.83 & 0.89 \\
\hline Final model & 0.84 & 0.84 & 0.00 & 1.00 & 1.00 & 0.99 & 1.00 & 1.00 & 1.00 \\
\hline
\end{tabular}
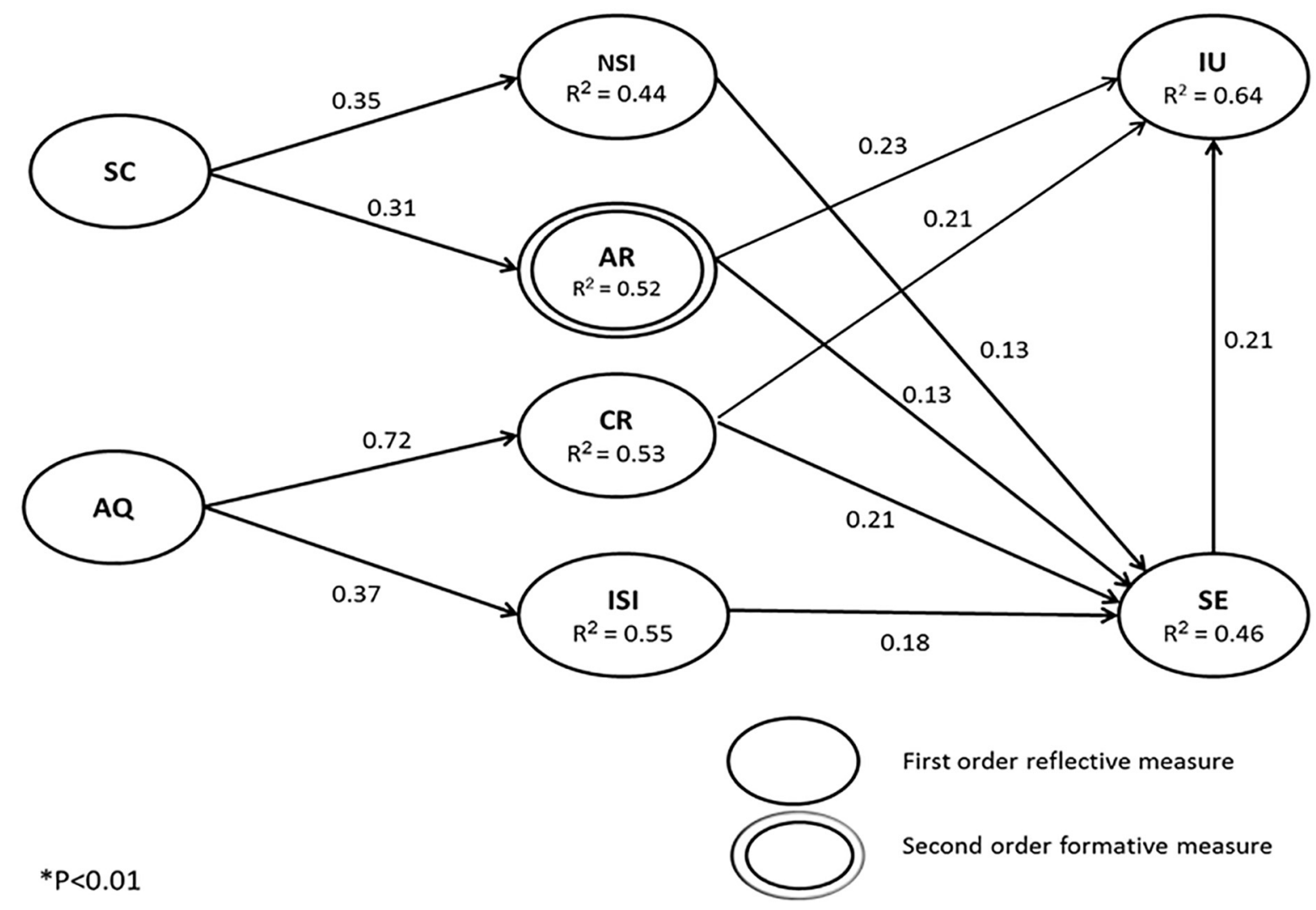

Figure 2. The final model of this study

\section{Discussion}

Understanding the factors that encourage users to use the information system is very important. In the marketing research, reports have been shown that persuasive messages, play a significant role in influencing employees' attitude change. Source credibility refers to a message source's perceived ability or motivation to provide accurate and truthful information (24). The results of this study suggest that source credibility stimulated the affective response. In other words, employees who have a higher level of source credibility should excite affective response users to continue using the HIS. The findings of this study were consistent with other studies (25). The previous studies have shown that source credibility is empirically linked with attitude and behavioral intent in the field of information technology (26). Additionally, Bhattacherjee and Sanford (2006) argued that source credibility may enhance user's affection through celebrity endorsement (27). Managers within the organization as a "hero" are able to encourage their staff to use technology. However, all information sources are not equally effective in shaping user's perceptions of information system implementation. Managers need to provide the appropriate data about the user's level of participation and information-processing routes, and use this knowledge to move employees toward successful information system implementation. Plausible strategies must be delivered to the employees based on their characteristics. Source credibility of the convincing message has significant effects on normative social influence. This study was consistent with other studies (28). In other words, Employees who have a higher level of source credibility should excite normative social influence users to continue using the HIS. Social influence is defined as a change in an individual's thoughts, feelings, attitudes, or behavior that is resulted from interaction with 
another individual or a group. Deutsch and Gerard (1995) identified two types of social influence: normative and informational social influences (29). Normative influence has been conformity based on a person's desire to fulfill others' expectations, often to gain acceptance. When people are under the influence of subjective norms, it is expected to receive a high level of social pressure to perform or not perform the behavior. But, the informational social influence, is a psychological phenomenon where people assume the actions of others in an attempt to reflect the correct behavior for a given situation. When a person is in a situation where they are unsure of the accurate way to behave, they will often look to others for cues concerning the right behavior. When the people gain more information, they can adhere to do behavior with more confidence. The informational social influence is more influential than the normative social influence. When employees understand and experience high levels of the informational social influence of the benefit and ease of use of their hospital information system,, they will be more likely to use the HIS. Therefore, it is imperative for managers deciding to buy a new information system in order to improve the efficiency, effectiveness, and their organization's performance. Some major points should be considered, to persuade such employees with regard to normative social influence. First, the nature of persuasive message should be the group in order to gain more effect. Second, the integration rate of individuals is within the group. If the manager wants to keep loyalty in the group, it needs to try soothing in some aspects. Finally, the manager should pay special attention to group decision making of his/her message, influence. When an individual has accepted the information system and if friends, colleagues or peers provide more positive opinions, the individual promotes his/her information area and shifts his situation to a more successive and desirable situation than the others. As our results revealed, argument quality has a remarkable impact on the users' cognitive response and informational social influence. The findings from this study were consistent with the results of other studies (25). The results confirmed that both source credibility and argument quality were effective on convincing employees to the implementation of information systems in their organizations. However, according to Rucker and Petty, when attitudes are based on argument quality reasoning, messages are more effective than when they are based on source credibility (30). Therefore, if hospital managers want their employees to constantly have the necessary motivation to change behavior, it is necessary to provide persuasive messages together with the argument quality reasoning more than to just pay attention to the source credibility. The results confirmed that both cognitions (cognitive and affective response) and various types of influences (informational social and normative social influence) were statistically significant and were effective on self-efficacy. Roach believes that effective steps can be taken to promote self-efficacy in individuals by improving their self-belief (cognitive perception) and motivation (emotional perception) (31). When individuals believe in their efficacy, they acquire their information from various sources. We can find out our self-efficacy by comparing ourselves with others. However, the formation of selfefficacy is mainly affected by the experience of previous successful people to learn through social comparisons. Vries assessed the role of social influence on attitudes, self-efficacy, intention and previous behavior as the first, explaining smoking in adolescents (32). He believes that, since social influences can arouse in different ways, it is recommended that planners design prevention programs not only to investigate social influence of overt routes such as direct pressure from peers, parents, and media, but to examine covert routes such as benchmarking and the ability to deal with the ways of social influence. The results confirmed that self-efficacy had the significant effect on the intention to continue using the hospital information system. Also, many studies have come to the same conclusion about the effect of self-efficacy on behavior intention. In most studies, perceived self-efficacy is mentioned as a good predictor of intention to engage in behaviors. This construct is a very important predictor in the acceptance and use of information technology. When users believe that they have sufficient ability to use the hospital information systems, they use them faster and more frequently. Of course, more use of the hospital information systems leads to promotion of self-efficacy beliefs. Furthermore, this belief is a reason that they understand IT applications in hospital environments. It is important that we use information technology in our organizations. This positive outcome can be achieved only if such technology be used. Organizations providing health care, particularly hospitals, which find it necessary to use IT facilities and training their forces, should consider factors affecting the adoption of this technology and apply programs to promote their empowerment in terms of acceptance and intention to continue with its use. Also, the modification model demonstrated that both affective response and cognitive response are directly effective on behavior intention. These findings are consistent with Li's (2013) (25). He believes that perceptions of cognitive into emotional at implementation of hospital information systems are the more vital. However, Verplanken believes that emotional perceptions can be achieved much easier than cognitive ones because emotional perception is less complicated (33). Therefore, it is essential to organizational managers to implement the hospital information system ad pay more attention to the cognitive perception of their employees. True perception of the system is followed by system acceptance. Since strong management support represents a key to building a more conducive environment for system success, managers should use different solutions to familiarize 
the users rightly and positively with the system (34). For instance, they should familiarize the users with the system's potential, possibility to support the system, procedure promotion, decrease in costs, etc.

\section{Limitation}

The findings from this study should be interpreted in light of several limitations. This study focused on implementing the hospital information system on the users of HIS in three companies (Tiraje computer, Mykroafzar Qeshm and Peivand data). This study reflects the intention of continuing the use of hospital information systems only in public hospitals of nurses. To collect data, this study focused on convenience sampling. Finally, all constructs of our model have emerged from the integration of several theories.

\section{Conclusions}

Hospital managers should largely looked forward to meeting the needs of emotional and cognitive perceptions of the clinical nurses and promote their self-efficacy and provide information from diverse sources and routes, such as informational and normative influence to improve the quality of health care delivery, improve productivity and increase the efficiency of its employees and also reduce hospital costs. Therefore, it's necessary to design mechanisms to influence evidence-based processes using this model so that nursing staff can continually increase the use of hospital information system.

\section{Acknowledgments:}

This article is part of a health information technology M.Sc. thesis. The authors wish to express their thanks to Kashan University of Medical Sciences for funding this project under the number 93090. Furthermore, we deeply appreciate all clinical nurses of the public hospitals for their genuine collaboration and participation in the conduct of this research.

\section{Conflict of Interest:}

There is no conflict of interest to be declared.

Authors' contributions:

All authors contributed to this project and article equally. All authors read and approved the final manuscript.

\section{References:}

1) Cline GB, Luiz JM. Information technology systems in public sector health facilities in developing countries: the case of South Africa. BMC Med Inform Decis Mak. 2013; 13(1): 13. doi: 10.1186/14726947-13-13. PMID: 23347433, PMCID: PMC3570341.

2) Ahmadi M, Kaldi AR. Study of the Feeling of Social Security of Women in Sanandaj City and Social Factors affecting on it. Sociology of women. 2013; 3(12): 1-19.

3) Mirza AA. Failure and success factors of an information system development in a charitable organization. Global Journal of Management And Business Research. 2010; 10(3): 79-83.

4) Hassibian MR. Electronic Health Records Acceptance and Implementation in Developing Countries: Challenges and Barriers. Razavi International Journal of Medicine. 2013; 1(1): 6-11. doi: 10.17795/rijm15077.

5) Clayton PD. Obstacles to the Implementation and Acceptance of Electronic Medical Record Systems. Building a Better Delivery System: A New Engineering/Health Care Partnership. 2005.

6) Park SY, Nam MW, Cha SB. University students' behavioral intention to use mobile learning: Evaluating the technology acceptance model. British Journal of Educational Technology. 2012; 43(4): 592-605. doi: 10.1111/j.1467-8535.2011.01229.X.

7) Shih CL, Fan YL, Shen YT, Li YL, Horng CT, Chen IC, et al. Our Experience on the Influence of TaskTechnology Fit Model on the Performance of Nursing Information System in Armed Forces General Hospital in Taiwan, Republic of China. Life Science Journal. 2014; 11(10): 1166-75.

8) Nazari F, Khosravi F, Babalhavaeji F. Applying Rogers' Diffusion of Innovation theory to the acceptance of online databases at University Zone of Iran. Malaysian Journal of Library \& Information Science. 2013; 18(3): 25-38.

9) Petty RE, Cacioppo JT. The elaboration likelihood model of persuasion. Advances in Experimental Social Psychology Journal. 1986; (19): 123-205.

10) Bhattacherjee A, Sanford C. Influence processes for information technology acceptance: An elaboration likelihood model. MIS quarterly. 2006: 805-25. 
11) Deutsch M, Gerard HB. A study of normative and informational social influences upon individual judgment. The journal of abnormal and social psychology. 1955; 51(3): 629-36. doi: 10.1037/h0046408.

12) Ratten V, Ratten H. Social cognitive theory in technological innovations. European Journal of Innovation Management. 2007; 10(1): 90-108. doi: 10.1108/14601060710720564.

13) Bandura A. Self - efficacy. Wiley Online Library. 1994.

14) Venkatesh V. Determinants of perceived ease of use: Integrating control, intrinsic motivation, and emotion into the technology acceptance model. Information systems research. 2000; 11(4): 342-65. doi: 10.1287/isre.11.4.342.11872.

15) Farzandipour M, Meidani Z, Gilasi H, Dehghan banadaki R. Ranking of hospital information systems based on requirements of Iran in 2014. Journal of Modern Medical Information Science. 2015; 1(1): 1-9.

16) Wilson FR, Pan W, Schumsky DA. Recalculation of the critical values for Lawshe's content validity ratio. Measurement and Evaluation in Counseling and Development. 2012; 45(3): 197-210. doi: 10.1177/0748175612440286.

17) Shi J, Mo X, Sun Z. [Content validity index in scale development]. Zhong Nan Da Xue Xue Bao Yi Xue Ban. 2012; 37(2): 152-5. doi: 10.3969/j.issn.1672-7347.2012.02.007. PMID: 22561427.

18) Santos JRA. Cronbach's alpha: A tool for assessing the reliability of scales. Journal of extension. 1999; 37(2): 1-5.

19) Raykov T. Evaluation of convergent and discriminant validity with multitrait-multimethod correlations. Br J Math Stat Psychol. 2011; 64(1): 38-52. doi: 10.1348/000711009X478616. PMID: 21506944.

20) Fornell C, Larcker DF. Evaluating structural equation models with unobservable variables and measurement error. Journal of marketing research. 1981; 18(1): 39-50. doi: 10.2307/3151312.

21) Kline RB. Principles and practice of structural equation modeling. Guilford publications. 2015.

22) Jöreskog K, Sörbom D. LISREL 8.5 [software]. Chicago, Ill: Scientific Software International. 2001.

23) Moss S. Fit indices for structural equation modeling. Accessed April 3 2013. http://www.psychit.com.au/Psychlopedia/article.asp? id=277. 2009.

24) Li CY. Persuasive messages on information system acceptance: A theoretical extension of elaboration likelihood model and social influence theory. Computers in Human Behavior. 2013; 29(1): 264-75. doi: 10.1016/j.chb.2012.09.003

25) Johnston A, Warkentin M. The influence of perceived source credibility on end user attitudes and intentions to comply with recommended IT actions. Journal of Organizational and End User Computing. 2010; 22(3): 1-21. doi: 10.4018/joeuc.2010070101.

26) Chung N, Han H, Koo C. Tourists' Attachment Processes and Behavioral Changes in Social Media: Persuasion and Reference Group Influence Perspective. PACIS. 2013.

27) Rucker DD, Petty RE. Increasing the effectiveness of communications to consumers: Recommendations based on elaboration likelihood and attitude certainty perspectives. Journal of Public Policy \& Marketing. 2006; 25(1): 39-52. doi: 10.1509/jppm.25.1.39.

28) Roach JB, Yadrick MK, Johnson JT, Boudreaux LJ, Forsythe WA, Billon W. Using self-efficacy to predict weight loss among young adults. Journal of the American Dietetic Association. 2003; 103(10): 1357-9. doi: 10.1016/S0002-8223(03)01072-1.

29) Vries HD, Backbier E, Kok G, Dijkstra M. The Impact of Social Influences in the Context of Attitude, Self - Efficacy, Intention, and Previous Behavior as Predictors of Smoking Onset1. Journal of Applied Social Psychology. 1995; 25(3): 237-57. doi: 10.1111/j.1559-1816.1995.tb01593.x.

30) Phillips J, Gully S. Organizational behavior 2e. Tools for success: Cengage Learning. 2011.

31) Kamran F, Ebadati Nazarloo S. Evaluation of socio-economic factors affecting in peace and social security among female students at University of Tehran International Journal of Business and Social Science. 2011; 3(6): 43-55.

32) Verplanken B, Hofstee G, Janssen HJ. Accessibility of affective versus cognitive components of attitudes. European Journal of Social Psychology. 1998; 28(1): 23-35. doi: 10.1002/(SICI)10990992(199801/02)28:1<23::AID-EJSP843>3.0.CO;2-Z 